\section{ON TAP}

The Marcellus shale contains about 2.4 trillion cubic metres of recoverable natural gas.

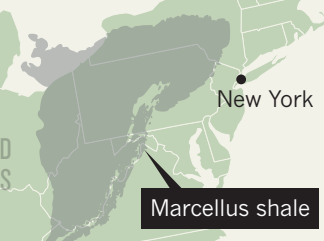

on whether the gas was produced by microorganisms in relatively shallow water or by heat and pressure deep in the Earth. The team also looked at the relative concentrations of ethane, propane and helium - other common by-products of gas extraction that are rare in shallow groundwater sources.

The results suggest that homeowners living up to 1 kilometre from shale-gas wells probably have groundwater contaminated by gas from the Marcellus Formation. But the team did not find evidence that chemicals used in fracking migrated from depth to contaminate aquifers. Jackson says that the methane is probably from leaks in the well casing itself, which would allow direct contamination. The data also suggest that some gas migrated up from geological layers between the Marcellus Formation and the groundwater table.

The data "raise important issues", says Mark Zoback, a geophysicist at Stanford University in California, who served on a high-level panel that in 2011 recommended improving industry practices to minimize environmental impacts. "There's a real need in the future to have this kind of sampling before, during and after shale-gas development."

Officials from Cabot, which operates most of the wells in this area, declined to comment on the study. Steve Everley, a spokesman for Energy In Depth, a research and advocacy arm of the Independent Petroleum Association of America, based in Washington DC, says the Duke study is inconclusive. He notes that recent baseline testing by the US Geological Survey found non-microbial methane in two groundwater wells in northeastern Pennsylvania even before drilling.

Jackson says that his results do not necessarily mean that all drilling operations will have problems. Other research by his team, now in the press in Applied Geochemistry, found no evidence of contamination in a shale formation in Arkansas. More importantly, he says, the results suggest that the problem is relatively simple to fix.

"This is about well integrity," he says. "The industry knows how to do this, and they work hard to maintain well integrity."

ELECTROCHEMISTRY

\title{
Sulphur back in vogue for batteries
}

\section{Lithium-sulphur batteries benefit from new materials.}

\section{BY RICHARD VAN NOORDEN}

A type of battery first proposed in the 1960 s is attracting a fresh surge of interest as scientists and engineers look for ways to extend the range of electric vehicles. The veteran system is the lithium-sulphur battery, now back in fashion as the limitations of expensive, low-capacity lithium-ion batteries become ever more apparent. Over the past two years, what was a trickle of publications has gathered into a wave (see 'The lithiumsulphur charge') as scientists wear down oncemajor stumbling blocks, and the area attracts more funding.

Chemists say that there is substance to the buzz. Although researchers are wary of overstating the case, "we believe that lithiumsulphur is the way to go", says Ilias Belharouak, a materials scientist who works on batteries at Argonne National Laboratory in Illinois. "There's promise from many different labs and some approaches really are working," adds Linda Nazar, a chemist who studies lithiumsulphur batteries at the University of Waterloo in Ontario, Canada.

Lithium-ion batteries, as their name suggests, shuttle lithium ions from one electrode to another, while forcing electrons around an outside circuit. Improving the energy-density of that system means finding a material that can hold more lithium. Decades ago, sulphur was tipped as a promising candidate ${ }^{1}$. It is cheap, abundant and can bond to large numbers of lithium ions. In theory, a battery with a metal lithium anode and a sulphur-based

\section{THE LITHIUM-SULPHUR CHARGE}

The number of research papers on lithiumsulphur batteries is rising fast.

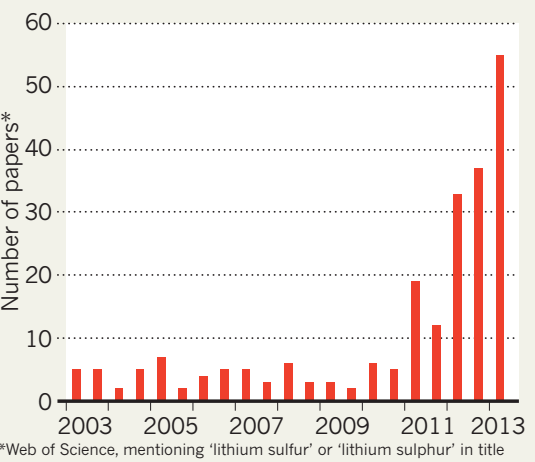

cathode can hold as much as five times the energy density of today's batteries, in which lithium ions are held (but not chemically bonded) within the pores of both the carbon and the metal-oxide-based electrodes (see 'How batteries stack up'). That translates into a greater range for vehicles.

So far, no one has managed to commercialize a lithium-sulphur battery that works well for more than a few dozen charging cycles. The problems are numerous: sulphur does not conduct ions well, so it is hard to get the lithium to move through the sulphur to exploit the whole cathode. And when the lithium ions do start bonding to sulphur atoms, they form soluble compounds - polysulphides - that dissolve in the electrolyte (the liquid through which the ions shuttle). As a result, the sulphur electrode gradually crumbles and the battery loses capacity as it is recharged. Moreover, the lithium metal electrode itself is reactive, although some companies, such as PolyPlus in Berkeley, California, have invented materials to protect it.

Some of these obstacles are now giving way. In 2009, Nazar's lab showed how to connect the lithium and sulphur atoms more closely by holding the sulphur within a dense network of carbon fibres a few nanometres apart ${ }^{2}$. Coating those same structures with water-loving polymers helped to trap the polysulphide products. Since then, hundreds of papers have reported related ways of structuring the electrode to function more efficiently.

In January, Yi Cui of Stanford University in California, and his team reported that sulphur nuggets held in titanium dioxide shells - like yolks protected in porous eggshells - maintained $70 \%$ storage capacity after 1,000 charging cycles ${ }^{3}$. And earlier this month, Chengdu Liang's group at the Oak Ridge National Laboratory in Tennessee, reported a new sulphurbased solid that conducts lithium ions ${ }^{4}$. A liquid electrolyte is no longer needed, Liang says, preventing the problem of soluble polysulphides altogether, and perhaps creating a safer system.

Jay Akhave, who works for the battery firm Altairnano in Reno, Nevada, says that Liang's find is a "key breakthrough", although other researchers disagree. Steven Visco, chief executive of PolyPlus, argues that Liang's new compound - in which long sulphur chains hang off a phosphorus-sulphur molecule - will not survive hundreds of charging cycles. 
Industrial lithium-sulphur firms are also bullish. At PolyPlus, Visco says that the firm's protective lithium material is advancing batteries that cycle lithium ions through sea water - although not for many cycles. Other companies working hard include Sion Power in Tuczon, Arizona (now partly owned by German chemical firm BASF), and Oxis Energy, at the Culham Science Centre in Abingdon, UK.

Last year, these three firms separately announced a total of US\$90 million in new investment, of which some $\$ 15$ million came from US federal grants. Another funding boost will come from a new US Department of Energy hub - the Joint Center for Energy Storage, based at Argonne - which aims to make batteries five times more powerful and $80 \%$ cheaper within five years. It has $\$ 120$ million to give out in research grants, but is not specifically focused on lithium-sulphur.

First sales of prototype batteries are likely to be to military and defence markets, for use in such applications as military drones,

\section{HOW BATTERIES STACK UP}

No battery can beat the energy density and power of petrol (gasoline) but lithium-sulphur batteries would outperform lithium-ion ones.

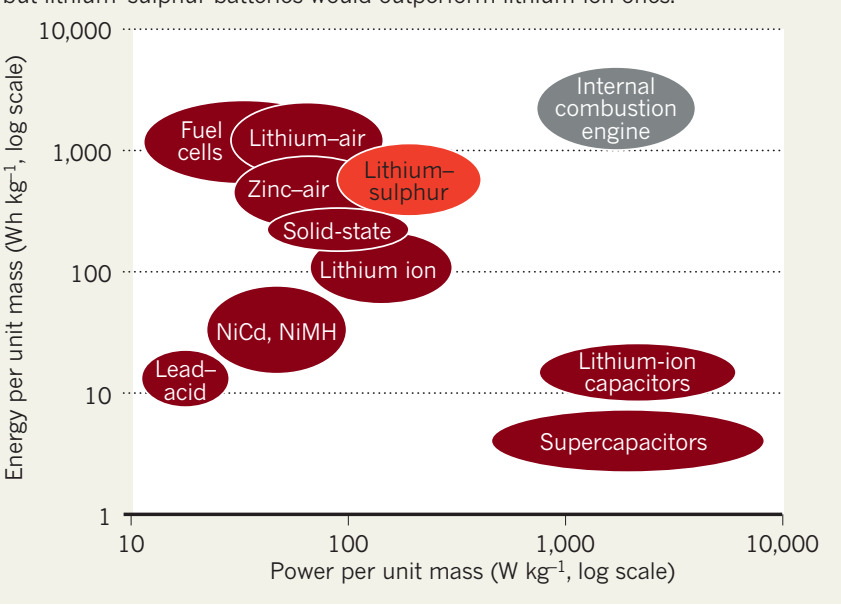

the field suffers from hype - with academic discoveries often blurring key details, such as battery currents, to highlight one or two impressive numbers. "We need a concerted effort to make sure cells are standardized, so that we are comparing the same things when reporting data," says Nazar.

Nonetheless, sulphur is edging ahead of other futuristic battery designs, such as the high-energydensity lithium-air battery - in which lithium ions bind to oxygen sucked in from the atmosphere. There, the ions are hard to recover for recharging and tend to be poisoned by other atmospheric gases.

In that field, says Nazar, scientists are still finding out about the problems. where the high energy densities and relative safety are more important than the thousands of charge cycles a commercial electric car requires. Researchers do not expect to see a commercial lithium-sulphur battery before the end of the decade. Clever nanostructuring that works in the lab may be too expensive as an industrial proposition. And
1. Yamin, H., Gorenshtein, A., Penciner, J., Sternberg, Y. \& Peled, E. J. Electrochem. Soc. 135, 1045-1048 (1988).

2. Ji, X., Lee, K. T. \& Nazar, L. F. Nature Mater. 8 , 500-506 (2009).

3. Seh, Z. W. et al. Nature Commun. 4, 1331 (2013).

4. Lin, Z., Liu, Z., Fu, W., Dudney, N. J. \& Liang, C. Angew. Chem. Int. Edn http://dx.doi.org/10.1002/ anie.201300680 (2013).

\section{BY ERIKA CHECK HAYDEN}

$\mathrm{H}$ IV-positive mothers who take antiretroviral therapies while pregnant can be prevented from transmitting the virus to their babies $99 \%$ of the time - a resounding success story in the decades-long fight against the virus. But what about infants whose mothers do not receive the drugs? Energized by the case of the 'Mississippi baby' - who seemed to be cured of HIV after aggressive treatment was begun within hours of birth - researchers are hoping to show that these infants, too, can get off to a healthy start.

At a symposium on HIV cure research on 29 June at the International AIDS Society's biennial meeting in Kuala Lumpur, Malaysia, investigators will describe how they are racing to design a clinical trial to test whether the early treatment works, and why. They hope to treat the first babies by the end of this year.

The trial, sponsored by the International Maternal Pediatric Adolescent AIDS Clinical Trials (IMPAACT) Group, marks a change for the field: so far, most research worldwide has focused on adults. In 2012, the US National Institute of Allergy and Infectious Diseases in Bethesda, Maryland, spent US $\$ 18$ million on HIV cure research in adults and adolescents, and just $\$ 45,000$ on children. Yet 3.3 million children worldwide have HIV.

"Children have been an afterthought," says Jeffrey Safrit, director of clinical and basic research for the Elizabeth Glaser Pediatric AIDS Foundation, who is based in Los Angeles, California. "But the immune system of the child might be more easily manipulated to allow a cure."

This was highlighted in March, when virologist Deborah Persaud of the Johns Hopkins Children's Center in Baltimore, Maryland, announced that a baby in Mississippi who received treatment for HIV within 31 hours of birth stopped medication at 18 months without the virus rebounding (see Nature http://doi.org/ $\mathrm{m} 2 \mathrm{~d} ; 2013)$. Researchers knew that early treatment could help infants to control HIV, but were surprised that they could essentially wipe it out from an infant's body using existing drugs.

Early HIV treatment is helpful for patients

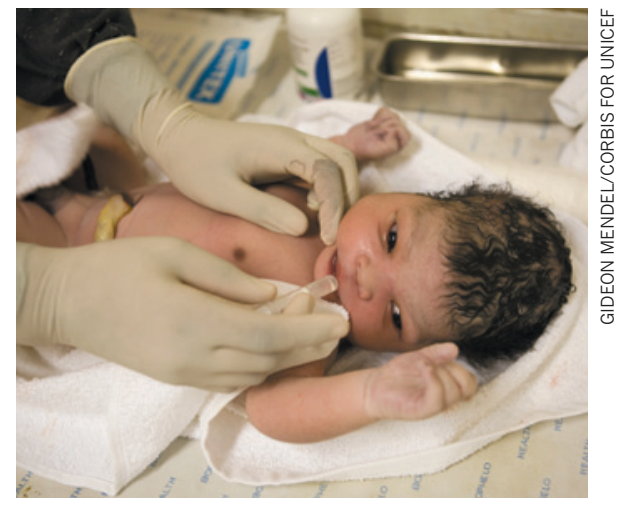

A baby in Lesotho is given anti-HIV drugs at birth.

of any age. It stops the virus from replicating before it can infect central memory T cells, the main immune-cell reservoir where HIV 'hides' from drugs. But researchers think that babies are better targets for HIV cures than adults because of their immature immune systems, which respond more mildly when provoked. Because the cells involved in this 'inflammatory response' are the same ones that are 